\title{
The Todaro Paradox: An Econometric Test Using Data from Congo
}

\author{
Samuel Ambapour \\ General Manager, Institut National de la Statistique, Republic of Congo \\ Email: ambapour_samuel@yahoo.fr \\ Received 20 June 2015; accepted 7 August 2015; published 10 August 2015 \\ Copyright (C) 2015 by author and Scientific Research Publishing Inc. \\ This work is licensed under the Creative Commons Attribution International License (CC BY). \\ http://creativecommons.org/licenses/by/4.0/ \\ c) (i) Open Access
}

\begin{abstract}
In this paper we test on data from Congo, what is come to know as Todaro Paradox. That is, on the one hand, the idea is put forward by Lewis that, industrial expansion will allow developing countries to reduce unemployment caused by an oversized rural workforce. However, on the other hand, Harris and Todaro argue that expanding urban employment will attract the rural population into the cities thus increasing unemployment. Our result seems to confirm Lewis' theory that urban job creation leads to lower unemployment.
\end{abstract}

\section{Keywords}

Urban Unemployment, Technological Dualism, Migratory Flow, General Equilibrium Model, Returns to Scale

\section{Introduction}

In the mid-fifties, Lewis [1] [2] put forward the idea that, industrial expansion would allow developing countries to reduce unemployment caused by an oversized rural workforce. Unlike Lewis, relying on a theoretical model, Harris and Todaro, in the early nineteen-seventies, argued that expanding urban employment would attract the rural population into the cities thus increasing unemployment. This was referred to the Todaro Paradox. Recently, the scope of the conflicting conclusions between Lewis and Harris/Todaro was assessed by Cahuc and Célimène (henceforth C \& C) [3], using a theoretical two sector general equilibrium models with endogenous salaries. This assessment revealed that the relationship between the modern sector's expansion and unemployment strongly depended on each sector's returns to scale. The model's relevance was tested on a sample of seventeen Latin American and Caribbean countries revealing situations imagined by both Lewis and Todaro. Applied on data from Congo, this model seemed to confirm Lewis' theory that urban job creation led to lower unemployment. 
The remainder of this paper was therefore the following: in Section 2, we presented a brief literature review followed by the model. In Section 3, the two specifications adopted by C \& C from their theoretical model are described. The first specification concerns the nature of the returns to scale and explores the relationship between the level of employment and the apparent productivity of work in the modern and traditional sectors. The second functional form allows estimating the relationship between the unemployment rate and the proportion of jobs in the modern sector within the total active population. In section 4, after presenting the data, empirical tests are made on data from Congo. The results obtained show that the impact of modern sector job creation on unemployment is inferably ambiguous. However, these econometric results combined with certain characteristics of the Congolese economy, seem to favor the thesis of Lewis whereby urban job creation leads to lower unemployment. Our concluding remarks follow in Section 5.

\section{Literature Review}

In a famous 1954 paper, the 1979 Economics Nobel Prize winner, Lewis, [1] [2] presented for the first time his technological dualism theory. The article explains that in the under-developed economy there are two sectors: the capitalist sector using modern technology on the one hand and the traditional subsistence sector with its structural surplus of labor on the other. Lewis formulated a thesis that industrial expansion would allow reducing unemployment caused by an oversized rural workforce. However, Lewis' approach is purely qualitative. His model is not formalized [4] and he did not set up a rigorous framework to study migration and urban unemployment mechanisms [4]. Consequently, fifteen years later, Todaro [5]-[7] and then Harris and Todaro [8], still relying on technological dualism and a theoretical model built to study migrations from the countryside to the city stemming from the gap between the salaries of the two sectors, put forth a contrary argument: an increase in urban employment would result in an increase in unemployment. This is referred to as the Todaro Paradox. Since then, this paradox has been the subject of numerous critical analyses and interesting extensions. For Assidon [9], the importance of the Todaro model stems from the revelation, as soon as the seventies, that urban unemployment in the Third World was rising and the rural exodus was accelerating in most of the African and Latin American countries. This is a classic analysis of the effect of a fixed sectoral wage rate [10]; the model accepts the hypothesis that the wage rate, based on exogenous factors, is high in the urban sector, but that wages in the rest of the economy are flexible.

Several commentators have shown that the validity of Todaro's model depends on how migration flows are taken into account and how the balance of these flows is influenced by unemployment. In fact:

- Todaro [7] later wrote that his model was only justified if migration was more flexible towards the probability of finding urban employment. For Zarembaka [11], recognition of this probability is the most essential part of the model.

- Blomqvist [12] proposed a model in which migrations are considered a partial adjustment mechanism. He thus integrated into a single model the short and long-term effects of urban job creation, taking into account workforce turnover in the sector. In the short term, his model confirms the Todaro proposal. In the long term, if the workforce turnover rate is high and if migration is limited, this proposal may be rejected.

- Arellano [13] summarized the various approaches and compared their short and medium-term implications. He showed that the long-term effects were crucially dependent on the specification representing migration flow and the time horizon.

- According to Nakagome (see [3]), job creation not only leads to increased migration, but also to a spatial expansion of the urban labor market. And that expanding the labor market by reducing marginal transportation costs would reinforce the migration phenomenon and tend to increase unemployment.

In a different direction, urban wage variations were introduced into the Todaro model [14]. Indeed, by considering the salary variable, the Todaro model was significantly improved. The common feature of all previous approaches was the fact that wages were considered constant in the modern sector. Endogenizing salaries, therefore, allowed explaining certain phenomena.

This is how Stiglitz and Calvo (see [15]) extended the Harris and Todaro model by justifying salary rigidity in urban areas through a labor rotation model, or by the presence of a union. In fact:

- The modern sector's unionization could explain the wage gap between the modern sector and the traditional sector [16].

- The origin of this discrepancy could be regarded as a problem of controlling workers' efforts that require 
firms to pay relatively high wages. This wage incentive pushes workers to increase productivity in the modern sector. This hypothesis of a positive connection between wages and individual productivity is at the base of the efficient wage theory [17].

- The existence of labor cost rotation could explain the downward rigidity of wages in the modern sector, and therefore unemployment [3]).

Recently, in order to assess the scope of the antagonism between the conclusions of Lewis and those of Harris and Todaro concerning the relationship between the modern sector's expansion and unemployment in a dual economy, C \& C, using a theoretical two-sector model of general equilibrium with endogenous wages, showed that [3]:

- This antagonism could be explained by the structural specificities of the different economies.

- This relationship would strongly depend on each sector's returns to scale.

This model allows identifying areas of relevance within Lewis' and Todaro's conclusions. The latter provided very satisfactory results when applied to data from Latin American countries.

According to Malinvaud [18], the clash between observation and theory has a dual function: on the one hand, it provides additional clarification, for example when it comes to estimating the value of a model's parameters, and on the other, it tests the reality of the theory. This text has this dual objective. Indeed, when seeking to test a theory, the same observation can be compatible with several theories; "thus, observation is suitable for contradicting a theory or falsifying it, according to the accepted expression. However, the prolonged absence of refutal, after repeated confrontations with separate data is practically an affirmation; the theory has not been proven by irrefutable factual evidence, but it has been corroborated" [18]. It is in this vein that we here propose to verify the theories of Lewis and Todaro using econometrics with data from Congo.

\section{The Model}

The model used to examine the antagonism between the conclusions of Lewis and those of Todaro concerning the relationship between the modern sector's expansion and unemployment in a dual economy based on theoretical framework of C \& C. According to C \& C, the negotiated wage character and technological dualism of underdeveloped economies is represented, not as an opposition between an urban and a rural sector, but between a modern industrial, private service and administrative sector and a traditional sector made up of agriculture and informal activities [19]. The analytical framework is that of a two-sector inter temporal general equilibrium model with endogenous wages. It is thus shown that the impact of industrial job creation on unemployment crucially depends on externalities induced by changes in the number of jobs affecting the returns to scale of each sector. According to C \& $\mathrm{C}$, the degree of influence of these externalities on the relationship between modern sector employment and unemployment can be seen:

- On the one hand by assessing the nature of each sectors' returns to scale.

- And on the other by estimating the influence of industrial employment variations on unemployment.

It is therefore a two-step approach:

- First, the nature of returns to scale is estimated by studying the equation linking the employment level and the apparent labor productivity in both sectors.

- Secondly, the unemployment rate is precisely modeled by the proportion of modern sector jobs in the total active labor force.

This second step intends to check if the elasticity of the modern sector's unemployment rate relative to the employment rate agrees with the theoretical model.

Before specifying the two steps, let us first define the notations used to characterize the selected variables. These variables are as follows:

$L_{1}=$ Employment in industry, trades, market and non-market services; $L_{2}=$ Employment in agriculture and other traditional activities; $N=$ Total labor force; $U=$ Number unemployed; $Q_{1}=$ Production valued according to industry, trade, market and non-market service cost factors; $Q_{2}=$ Production valued according to agriculture and other traditional activity cost factors; $\frac{Q_{1}}{L_{1}}=$ Productivity in the modern sector; $\frac{Q_{2}}{L_{2}}=$ Productivity in the traditional sector; $\frac{L_{1}}{N}=$ Share of employment in the modern sector; $\frac{U}{N}=$ Unemployment rate.

The two equations estimated in the first stage are as follows: 


$$
\ln \frac{Q_{1 t}}{L_{1 t}}=\mu_{01}+\mu_{1} \ln L_{1 t}+\alpha_{1} \ln T \text { for the modern sector }
$$

and $\ln \frac{Q_{2 t}}{L_{2 t}}=\mu_{02}+\mu_{2} \ln L_{2 t}+\alpha_{2} \ln T$ for the traditional sector.

By deriving Equations (1) and (2) from the time, we obtain the following relationships between growth rates:

$$
\frac{\tilde{Q}_{1 t}}{L_{1 t}}=\mu_{1} L_{1 t}+\alpha_{1} \text { for the modern sector }
$$

and $\frac{\tilde{Q}_{2 t}}{L_{2 t}}=\mu_{2} L_{2 t}+\alpha_{2}$ for the traditional sector.

If $\mu_{i}>0$, returns to scale are increasing;

If $\mu_{i}<0$, returns to scale are decreasing;

$\alpha_{i}$ is a temporal trend that detects the effect of technical progress and capital intensity.

The only equation estimated in the second step is:

$$
\ln \left(\frac{U_{t}}{N_{t}}\right)=\beta_{0}+\beta_{1} \ln \left(\frac{L_{1 t}}{N_{t}}\right)
$$

Or by differentiation:

$$
\frac{\tilde{U}_{t}}{\tilde{N}_{t}}=\beta_{1}\left(\frac{L_{1 t}}{N_{t}}\right)
$$

According to the authors, "this specification does not take into account the flexibility induced by modern sector job creation on the labor force; however it does correspond to the theoretical model that defines the relationship between the number of modern sector jobs and the number of unemployed in labor force, without describing the mechanism used for determining the volume of the working population”. Note that in Equations (5) and (6), in order to obtain robust estimates, a temporal trend was sometimes added. Sometimes, as with equations (1) and (2), we also completed tests by integrating temporal offsets. This was to take into account the various delays in propagating external effects on:

- Returns induced by employment changes in the case of Equations (1) and (2);

- Unemployment induced by changes in the share of modern sector employment in the case of Equations (5) and (6).

It should be noted that the growth rate specifications are only retained if the series level estimates are not significant. This is often due to the explanatory variable collinearity as a consequence of smoothing the logarithm series. C \& C applied the above specifications to a sample of seventeen developing countries in Latin America and the Caribbean over the 1960-1988 period. The results comprehensively confirmed the relevance of their theoretical model. Returns in the modern sector are increasing or decreasing. However, only the assumption of decreasing returns in the traditional sector was confirmed. These results helped to reconcile the situations imagined by Lewis or Todaro. Indeed, we find:

- On the one hand, countries whose returns to scale in both sectors are decreasing and have negative unemployment elasticity compared with the proportion of jobs in the modern sector. In fact, these are countries characterized by a very strong rural population, an important traditional sector of over $60 \%$ of the active population that represents more than three quarters of the total value of exports and consumption habits related to local production. These are the characteristics of the countries studied by Lewis. In the sample of countries studied by C \& C, two countries match this description, El Salvador and Guatemala.

- On the other hand, countries whose returns to scale in the traditional sector are decreasing and increasing or decreasing in the modern sector and have a positive unemployment rate elasticity. These countries are characterized by a relatively important modern sector that is industrial or public sector, and attractive based on salary levels and development prospects. These countries include: Brazil, Mexico, and Argentina. 


\section{Tests on Congo data}

\subsection{Data}

Derived from the following two sources:

- The "World Table" of the World Bank. These are official World Bank Statistics on production estimated according to the cost of factors (labor and capital) in the two sectors studied. That is the modern industrial, private service and administrative sector and a traditional sector made up of agriculture and informal activities.

- Study report on the creation of the United Nations Development Program (UNDP) database [20] in relation to the number of unemployed, the overall workforce, employment in agriculture and other traditional activities, employment in industry, trade, and market and non-market services. These are estimates based on the results of economic and annual surveys of companies, administrations, national accounts and population censuses. The analysis covers the period from 1973 to 1993.

It should, however, be mentioned that when dealing with developing country data where the statistical system is still faulty, one should always bear in mind the risk of "statistical illusion" enunciated by Morgenstern (1950): "Without acknowledging the errors, introducing economic data into high speed computers is devoid of meaning [21]. The estimation results below should be interpreted with care because they are often subject to considerable uncertainties. Any result depends on the chosen sample, the data used, the selected period, and the methodology... In general, "the data are observed data, which means that a filtering of the observable world took place before handing the data over to the econometricians. This prior filtering of the econometrics puts into perspective the realism of any effort "to crunch the data". "Data does not speak: it is observed according to a certain interpretive framework; then, experts examine the observations and speak among themselves” [22].

\subsection{Estimates}

\subsubsection{Na-Ture of Returns to Scale}

The results of the estimates of Equations (1) and (2) by ordinary least squares (OLS) on Limdep software [23] are as follows:

—Modern sector;

$$
\begin{gathered}
\ln \left(\frac{Q_{1 t}}{L_{1 t}}\right)=-16.58+1.763 \ln L_{1 t}+2.150 \ln T \\
(-8.2) \quad(6.778) \quad(2.925) \\
R^{2}=0.031 ; \quad D W=0.72
\end{gathered}
$$

—Traditional sector;

$$
\begin{gathered}
\ln \left(\frac{Q_{2 t}}{L_{2 t}}\right)=33.272-5.075 \ln L_{1 t}+9.676 \ln T \\
(4.102) \quad(-6.271) \\
R^{2}=0.967 ; \quad D W=0.881
\end{gathered}
$$

It was noted that the returns in the modern and traditional sectors appear significantly different from zero according to the Student's test at a $5 \%$ confidence level and even by $1 \%$ ( $t$-statistic are in the brackets). It was also noted that the explanatory power of the model is good; however it is better in the traditional sector and thus confirms the assumption of diminishing returns in this sector. The assumption of the independence of errors is rejected at the 5\% threshold by the Durbin Watson test. Cochrane-Orcutt [23] method was deemed appropriate to correct for this autocorrelation of errors. We obtain:

—For the modern sector;

$$
\ln \left(\frac{Q_{1 t}}{L_{1 t}}\right)=-22.031+2.174 \ln L_{1 t}+2.242 \ln T
$$

—For the traditional sector; 


$$
\ln \left(\frac{Q_{2 t}}{L_{2 t}}\right)=25.936-4.125 \ln L_{2 t}+8.622 \ln T
$$

\subsubsection{Unemployment Rate Elasticity}

The unemployment rate elasticity compared to the proportion of jobs in the modern sector within the active population is negative. Indeed, the best specification obtained by OLS using limdep software is as follows:

$$
\begin{gathered}
\ln \left(\frac{U_{1}}{L_{t}}\right)= \\
(-6.136) \quad(-11.38) \quad(13.314) \\
R^{2}=0.92 ; \quad D W=1.171
\end{gathered}
$$

It can be seen that the unemployment rate elasticity compared with modern sector employment is significantly different from zero at the $5 \%$ and $1 \%$ threshold.

As the nature of returns to scale of each sector has an influence on the unemployment rate elasticity, generally we are reminded that the two conclusions drawn from the theoretical model are as follows:

- Firstly, if returns to scale are strongly decreasing in both sectors, modern sector job creation induces a decrease in unemployment.

- Secondly, if returns are slightly decreasing or increasing in both sectors, modern sector expansion causes a sharp increase in unemployment.

As already indicated, these two conclusions thus allow finding the situations imagined either by Lewis or by Todaro.

In the case of Congo, there are increasing returns in the modern sector and diminishing returns in the traditional sector. The unemployment rate elasticity compared to the proportion of jobs in the modern sector within the active population is negative. This last result, associated with those of returns to scale, represents a somewhat ambiguous scenario; a case not observed in the sample analyzed by C \& C concerning the Latin America countries. A closer analysis was made by dividing the time into two periods: 1973-1984 and 1985-1993. The first sub-period is characterized by the creation of a public, industrial and agro-industrial modern sector and the process actually started around 1965. During this sub-period, the share of modern sector employment increased by $4 \%$. The second sub-period corresponds to the Congolese Government's adoption of structural adjustment measures. We can see a destruction of jobs through the scaling down of certain public enterprises. The share of employment in the modern sector fell by $3 \%$. Thus, the application of the model on these two sub-periods only confirms the results of the analysis:

- Increasing returns in the modern sector;

- Decreasing returns in the traditional sector;

- Negative unemployment rate elasticity compared to the proportion of jobs in the modern sector within the active population.

A general conclusion to these results can be made by examining the breakdown of the active working population based on certain economic considerations [24]. On the first point, in fact, if we look at the structure of the active labor force during the period under review, we realize that close to $60 \%$ of it represents the traditional sector. This percentage is closer to $70 \%$ if one refers to the first sub-period. The UNDP report points out in this connection that [25]: "Despite the rudimentary nature of the cropping techniques and the low agricultural yields, the Congo remains a farming country, both in number as well as by its actual potential (half of the population lives off agriculture;” [26])... Logging remains one of the most productive providers of salaried jobs in Congo [20]. On the second point, we can say that the modern sector remains poorly developed. It is dominated by the extractive industry consisting mainly of petroleum, which, despite being the product of industrial extraction, is exported crude. Thus, despite increasing modern sector returns, we are not far from the characteristics of an underdeveloped economy described by Lewis.

\section{Conclusion}

The purpose of this text was to verify, through empirical tests using data from the Congo, the conclusions of 
Lewis and Todaro concerning the relationship between the unemployment rate and modern sector employment. To do so, we relied on the theoretical framework developed by C \& C. The results of econometric tests, taking into account certain characteristics of the Congolese economy, showed that urban jobs in the Congo lowered unemployment, thus confirming the thesis of Lewis.

\section{References}

[1] Lewis, W.A. (1954) Economic Development with Unlimited Supplies of Labour. The Manchester School of Economic and Social, 22, 139-191.

[2] Problèmes Economiques (1999) 1969-1999: L’économie à travers les prix Nobel. Problèmes Economiques, No. 2.637.

[3] Cahuc, P. and Celimène, F. (1993) L'expansion du secteur moderne diminue-t-elle le chômage dans les pays en développement? Economie \& Prévision, 108, 31-46. http://dx.doi.org/10.3406/ecop.1993.5606

[4] Sadoulet, E. (1983) Croissance inégalitaire dans une économie sous-développée. Librairie Droz.

[5] Todaro, M. (1969) A Model of Labor Migration and Urban Unemployment in Less Developed Countries. American Economic Review, 59, 138-148.

[6] Todaro, M. (1970) Labor Migration and Urban Unemploment: Reply. American Economic Review, 60, 187-188.

[7] Todaro, M. (1976) Urban Job Expansion, Induce Migration and Rising Unemployment. A Formulation and Simplified Empirical Test for LDC's. Journal of Development Economic, 3, 165-187. http://dx.doi.org/10.1016/0304-3878(76)90049-3

[8] Harris, R. and Todaro, M. (1970) Migration, Unemployment and Development: A Two Sector Analysis. American Economic Review, 60, 126-142.

[9] Assidon, E. (1992) Les Théories Economiques du Développement. Editions la Découverte.

[10] Azam, J.P. (1995) Une Politique de Développement pour l’Afrique : Programme de recherche. Dans “Quel avenir pour l'économie africaine” OCDE.

[11] Zarembaka, P. (1970) Labor Migration and Urban Unemployment: Comment. American Economic Review, 60, $184-186$.

[12] Blomqvist, A. (1978) Urban Job Creation and Unemployment in LDC's: Todaro vs Harris \& Todaro. Journal of Development Economics, 5, 3-18. http://dx.doi.org/10.1016/0304-3878(78)90039-1

[13] Arellano, J.P. (1981) Do More Jobs in the Modern Sector Increase Urban Unemployment? Journal of Development Economics, 8, 241-247. http://dx.doi.org/10.1016/0304-3878(81)90031-6

[14] Stark, O., Gupta, M. and Levhari, D. (1991) Equilibrium Urban Unemployment in Developing Countries: Is Migration the Culprit? Economics Letters, 37, 447-482. http://dx.doi.org/10.1016/0165-1765(91)90090-8

[15] Zajdela, H. (1990) Le dualisme du marché du travail, enjeux et fondements théoriques. Economie \& Prévision, 92, 31-43. http://dx.doi.org/10.3406/ecop.1990.5155

[16] Calvo, G. (1978) Unemployment and Wage Determination in LDC’s: Trade Union in the Harris-Todaro Model. International Economic Review, 16, 65-81. http://dx.doi.org/10.2307/2526394

[17] Perrot, A. and Zylberberg, A. (1989) Salaire d'efficience et dualisme du marché du travail. Revue Economique, 40, 5-20.

[18] Malinvaud, E. (1987) Voies de la recherche macroéconomique. Editions Odile Jacob, Paris.

[19] Esfahani, H.S. and Salehi-Ifahani, D. (1989) Effort Observability and Worker Productivity: Towards and Explanation of Economic Dualism. Economic Journal, 99, 818-836. http://dx.doi.org/10.2307/2233773

[20] PNUD (2000) Projet PRC 2000/551, Brazzaville.

[21] Morgenstern, O. (1950) L’illusion statistique, Précision et incertitude des données économiques. Traduction française, Dunod, 1972.

[22] Erkel-Rousse, H. (1995) Introduction à l'économétrie du modèle linéaire. Cours polycopié, ENSAE, Malakoff.

[23] Greene, W.H. (2000) Econometric Analysis. Prentice Hall, Upper Saddle River.

[24] Brasseur, J. (1993) Les nouveaux pays industrialisés. Armand Colin, Paris.

[25] PNUD (2002) Rapport National sur le développement humain 2002. République du Congo. Guerres, et après? Développement humain en situation de post conflit.

[26] Banque de France (1994) La Zone Franc, Rapport Annuel. 